\title{
A systematic review and meta-analysis of host genetic factors associated with influenza severity
}

\author{
Nina Van Goethem ${ }^{1,2^{*}}$, Célestin Danwang ${ }^{2}$, Nathalie Bossuyt ${ }^{1}$, Herman Van Oyen ${ }^{1,3}$, \\ Nancy H. C. Roosens ${ }^{4 \dagger}$ and Annie Robert ${ }^{2 \dagger}$
}

\begin{abstract}
Background: The severity of influenza disease can range from mild symptoms to severe respiratory failure and can partly be explained by host genetic factors that predisposes the host to severe influenza. Here, we aimed to summarize the current state of evidence that host genetic variants play a role in the susceptibility to severe influenza infection by conducting a systematic review and performing a meta-analysis for all markers with at least three or more data entries.

Results: A total of 34 primary human genetic association studies were identified that investigated a total of 20 different genes. The only significant pooled ORs were retrieved for the rs 12252 polymorphism: an overall OR of 1.52 (95\% Cl [1.06-2.17]) for the rs12252-C allele compared to the rs12252-T allele. A stratified analysis by ethnicity revealed opposite effects in different populations.

Conclusion: With exception for the rs 12252 polymorphism, we could not identify specific genetic polymorphisms to be associated with severe influenza infection in a pooled meta-analysis. This advocates for the use of large, hypothesis-free, genome-wide association studies that account for the polygenic nature and the interactions with other host, pathogen and environmental factors.
\end{abstract}

Keywords: Polymorphism, Influenza severity, Association, meta-analysis

\section{Introduction}

The severity of disease resulting from infection with influenza viruses can range from mild symptoms to severe respiratory failure. This variability is due to multiple host- and pathogen-related factors and the interplay between them. Clinical risk factors for severe influenza have been well documented [1-5]. Patient characteristics, such as age and the presence of comorbidities, are easily available for clinicians to estimate the risk of a

${ }^{*}$ Correspondence: nina.vangoethem@sciensano.be

${ }^{\dagger}$ Nancy H. C. Roosens and Annie Robert are shared last authors.

1 Scientific Directorate of Epidemiology and Public Health, Sciensano, J.

Wytsmanstraat 14, 1050 Brussels, Belgium

Full list of author information is available at the end of the article patient to develop severe complications. Beside these, healthcare organization [6] and access to (intensive) care can significantly impact the outcome of severe acute respiratory infections, and partly explain differences in mortality rates across countries [7]. Disease severity also varies from influenza season to season [8], depending on the intrinsic pathogenicity of the type and subtype of circulating viruses. For example, subtype A(H3N2) usually causes more deaths than $\mathrm{A}(\mathrm{H} 1 \mathrm{~N} 1)[9,10]$ or influenza $B$ infections $[10,11]$, and it is often more severe in the elderly $[12,13]$. We have recently demonstrated that adding viral genomic information to a predictive model on top of traditional clinical data, such as age and comorbidities, provides a more complete view on the predictors of 
severity of influenza infection, and results in an increased predictive accuracy [14]. However, a large part of the variation in disease severity observed between patients from the same country and within the same season remains unexplained. As in many other infectious diseases [1517], host susceptibility to severe influenza disease is partly determined by specific host genes [18-20] that are involved in viral replication [21], interferon response [15], or virus-induced systemic inflammation. Indeed, numerous genes potentially participate in diverse mechanisms against the viral response [22]. The World Health Organization (WHO) prioritizes the identification of host genetic factors that predispose the host to severe influenza [23]. This leads to a better understanding of the biological mechanisms behind the development of severe disease, which may reveal new therapeutic approaches and may enable effective targets for vaccine therapies. Thereby, future clinically useful predictive models should include host genetic determinants together with traditional information on host characteristics and viral genomic data. However, the identification of a polygenic predisposition requires a large sample size, both because of the small expected effect attributable to individual variants and because of the additive nature of these genetic effects [24].

Candidate genetic markers typically only demonstrate small effects in genetic association tests [25, 26]. Consequently, larger sample sizes or a meta-analysis that combines results from previous studies on the same exposure-outcome relationship, are necessary to detect those small or moderate genetic effects of polymorphisms [25]. We aimed at providing a systematic review of all studies addressing a relationship between host gene variants and susceptibility to severe influenza infection. Additionally, we aimed at finding a common effect across studies focusing on the same genetic variant.

\section{Results}

\section{Search results}

The study selection process is summarized as a PRISMA flow diagram in Fig. 1. A total of 1983 de-duplicated records were retrieved from the initial bibliographic database search. In addition, 19 records were identified through reference checking, hand searching and other reviews. A total of 34 manuscripts were included in the systematic review after the first and second screening round. From these, a total of 74 data points, of which 71 with available genotype counts, were extracted. A total of 15 studies had multiple data points as they investigated multiple genotypes and/or there was a possibility to perform multiple post-hoc stratifications of cases and controls according to severity. There was a total of four genetic polymorphisms that had at least three data entries and for which a meta-analysis was conducted.

\section{Study characteristics}

Additional file 1 presents the data extraction for all data points $(n=74)$, including the study characteristics, CSI score, genotype frequencies, HWE in controls, and recalculated ORs. There were a total of 20 different genes assessed by the included studies $(n=34)$, with most frequent results for interferon-induced transmembrane protein 3 (IFITM3) (n studies=11;32\%). Other genes investigated were $\mathrm{C}$-C motif chemokine receptor 5 $(C C R 5, n=4)$, Fc fragment of IgG receptor IIa (FCGR2A, $n=3)$, tumor necrosis factor $(T N F, n=1)$, toll-like receptor (TLR2/TLR3/TLR4, $n=2)$, complement decayaccelerating factor $(C D 55, n=2)$, surfactant protein (SFTPA1/SFTPA2/SFTPB, $n=2$ ), ST3 beta-galactoside alpha-2,3-sialyltransferase 1 (ST3GAL1, $n=1)$, angiotensin I converting enzyme $(A C E, n=1)$, complement $\mathrm{C} 1 \mathrm{q}$ binding protein (C1QBP, $n=1), \mathrm{C}-\mathrm{X}-\mathrm{C}$ motif chemokine ligand $14(C X C L 14, n=1)$, glycine decarboxylase (GLDC, $n=1)$, mannose binding lectin $2(M B L 2, n=1)$, natural killer gene $(N K G 2 C, n=1)$, transmembrane serine protease 2 (TMPRSS2, $n=1)$, and phosphoinositide-3 kinase (PI3K, $n=1)$. A total of 34 distinct markers were recorded in the database, but only four met the inclusion criteria of at least three data points available per marker and were used in the subsequent meta-analysis. The majority of included studies (76\%) was performed in influenza $\mathrm{A}(\mathrm{H} 1 \mathrm{~N} 1) \mathrm{pdm} 09$ positive patients. Among investigated data points, a total of 19 (26\%) investigated severity indicators (e.g., ICU admission, invasive ventilation or mortality) among hospitalized patients, 11 (15\%) focused specifically on mortality among hospitalized patients, $10(14 \%)$ on mortality among hospitalized and ambulant patients combined, 17 (23\%) on severity indicators among hospitalized and ambulant patients combined, and 17 (23\%) assessed the risk for hospitalization. From the total of 74 data points, 40 (54\%) were characterized by a post-hoc stratification of cases and controls. Out of the 34 data points with all three CSI score domains scored, only 5 (15\%) had a credible CSI score (i.e., having only A or B grades).

\section{Meta-analyses}

We performed a meta-analysis for four different markers, rs12252 and rs34481144 in the IFITM3 gene, rs333 in the CCR5 gene, and rs1801274 in the FCGR2A gene, in all four genetic models. Table 1 shows the noteworthy results for each of the markers. The only significant pooled odds ratios were retrieved for the rs12252 polymorphism from the IFITM3 gene. In the homozygous model, the odds for severe influenza disease was 


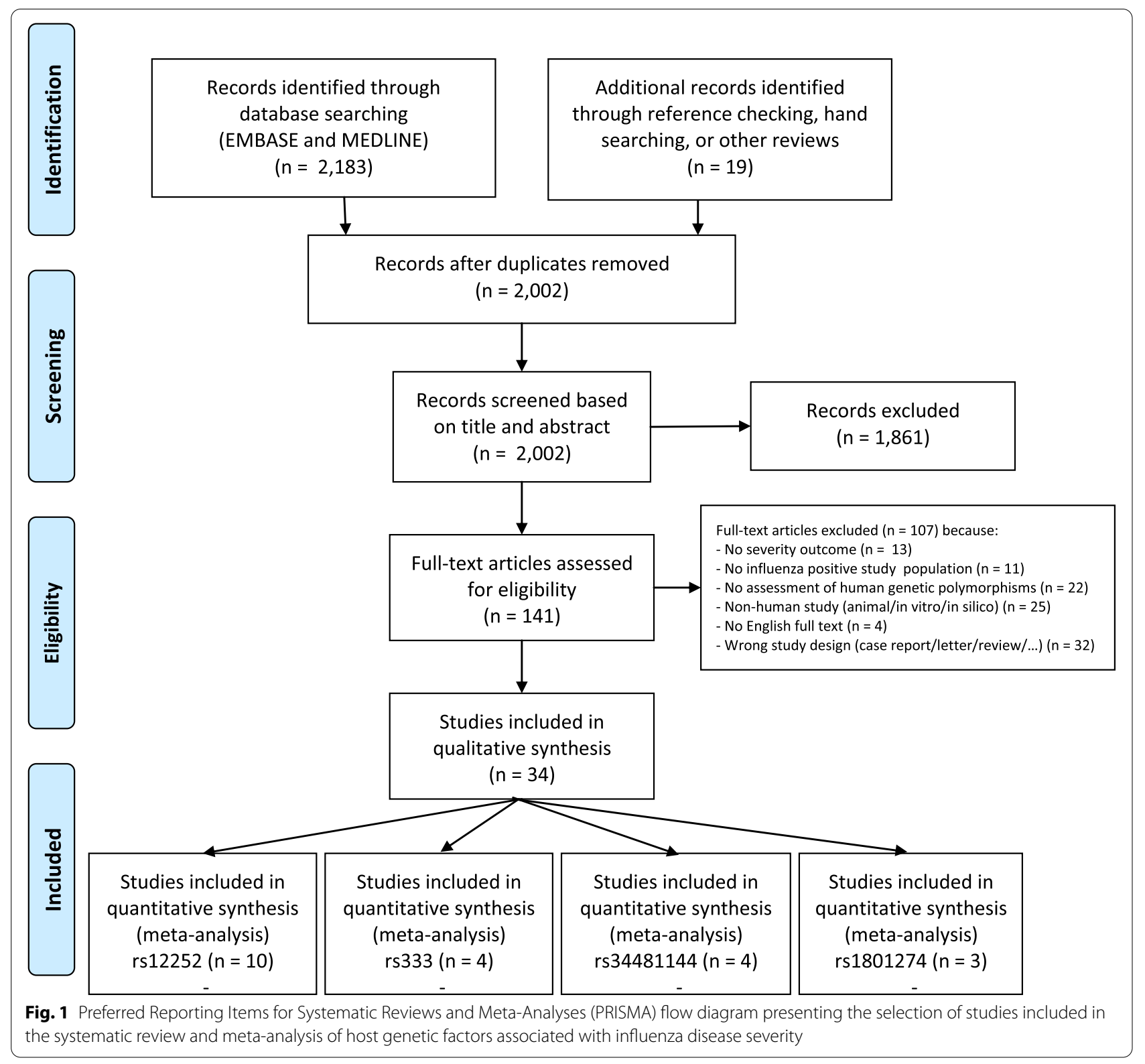

Table 1 Noteworthy results of meta-analyses assessing the association between host genetic factors and influenza disease severity. The entire set of results with meta-analyses performed using four different genetic models and stratified per ethnicity, study population or severity definition are available in Additional file 2

\begin{tabular}{|c|c|c|c|c|c|c|c|c|c|c|}
\hline Gene & rs code & Genetic model & Heterozygote & Risk allele & Studies (n) & $\begin{array}{l}\text { Cases } \\
\text { (alleles) } \\
\text { (n) }\end{array}$ & $\begin{array}{l}\text { Controls } \\
\text { (alleles) } \\
\text { (n) }\end{array}$ & $\mathrm{OR}^{\mathrm{a}}[95 \% \mathrm{Cl}]$ & $1^{2}$ & Venice score \\
\hline IFITM3 & rs12252 & Allelic & $\mathrm{CT}$ & C & 10 & 1422 & 2104 & $1.52[1.06 ; 2.17]$ & $54 \%$ & $\mathrm{BCC}$ \\
\hline IFITM3 & rs12252 & Homozygous & CT & C & 10 & 1422 & 2104 & $2.68[1.22 ; 5.88]$ & $29 \%$ & $\mathrm{BBC}$ \\
\hline CCR5 & rs333 & Dominant & $w t / \triangle 32$ & $\triangle 32$ & 4 & 934 & 990 & $1.20[0.10 ; 13.83]$ & $68 \%$ & $\mathrm{BCC}$ \\
\hline FCGR2A & rs1801274 & Allelic & $A G$ & G & 3 & 680 & 558 & $1.03[0.70 ; 1.53]$ & $0 \%$ & BAC \\
\hline IFITM3 & rs34481144 & Allelic & $A G$ & A & 4 & 540 & 872 & $1.47[0.24 ; 9.00]$ & $83 \%$ & $\mathrm{BCC}$ \\
\hline
\end{tabular}

OR Odds ratio, IFITM3 Interferon-induced transmembrane protein 3, CCR5 C-C motif chemokine receptor 5, FCGR2A FC fragment of IgG receptor lla

a Pooled random effect odds ratio calculated using Peto's method 
multiplied by 2.68 (95\% CI [1.22-5.88]) when having the $\mathrm{C} / \mathrm{C}$ genotype as compared to the T/T genotype. Similar results were obtained in the allelic model, with an overall OR of 1.52 (95\% CI [1.06-2.17]) for the rs12252$\mathrm{C}$ allele compared to the rs12252-T allele, albeit with more heterogeneity across studies $\left(\mathrm{I}^{2}=54 \%\right)$. Indeed, a stratified analysis by ethnicity revealed opposite effects in different populations: there was a 2.42 -fold (95\% CI [1.58-3.72]) increase in odds for severe influenza disease when having the rs12252-C allele within an Asian population, whereas the odds for severe influenza diseases when having the rs12252-C allele was decreased by $13 \%$ within a Caucasian population $(\mathrm{OR}=0.87,95 \%$ CI [0.81-0.93]) (Fig. 2). The pooled ORs were nonsignificant for the rs333, rs1801274, and rs34481144 polymorphisms in all genetic models and subgroup analyses. The leave-one-out analyses did not detect influential data points, nor did it change the conclusions. We also did not detect strong indications of publication bias in any of the meta-analyses. All metaanalyses, and the corresponding subgroup analyses, sensitivity analyses, and funnel plots, are available in Additional file 2.

\section{Discussion}

This systematic review and meta-analysis aimed to summarize the published evidence on the role of human genetic factors in influenza disease severity and subsequently sought a common effect across studies focusing on the same genetic variant. Several host genetic polymorphisms related to susceptibility to severe influenza disease have been studied and reported with varying levels of evidence. The included primary human genetic association studies, conducted within influenza positive patient cohorts, investigated whether patients with increased susceptibility to severe influenza disease had impaired intracellular control of viral replication (e.g. IFITM3 [27-37], TMPRSS2 [38] variants), defective interferon responses (e.g. GLDC [39] variants), polymorphisms in genes implicated in the cytokine response (e.g. TNF [40], CCR5 [41-44] variants), dysfunction of proteins related to the

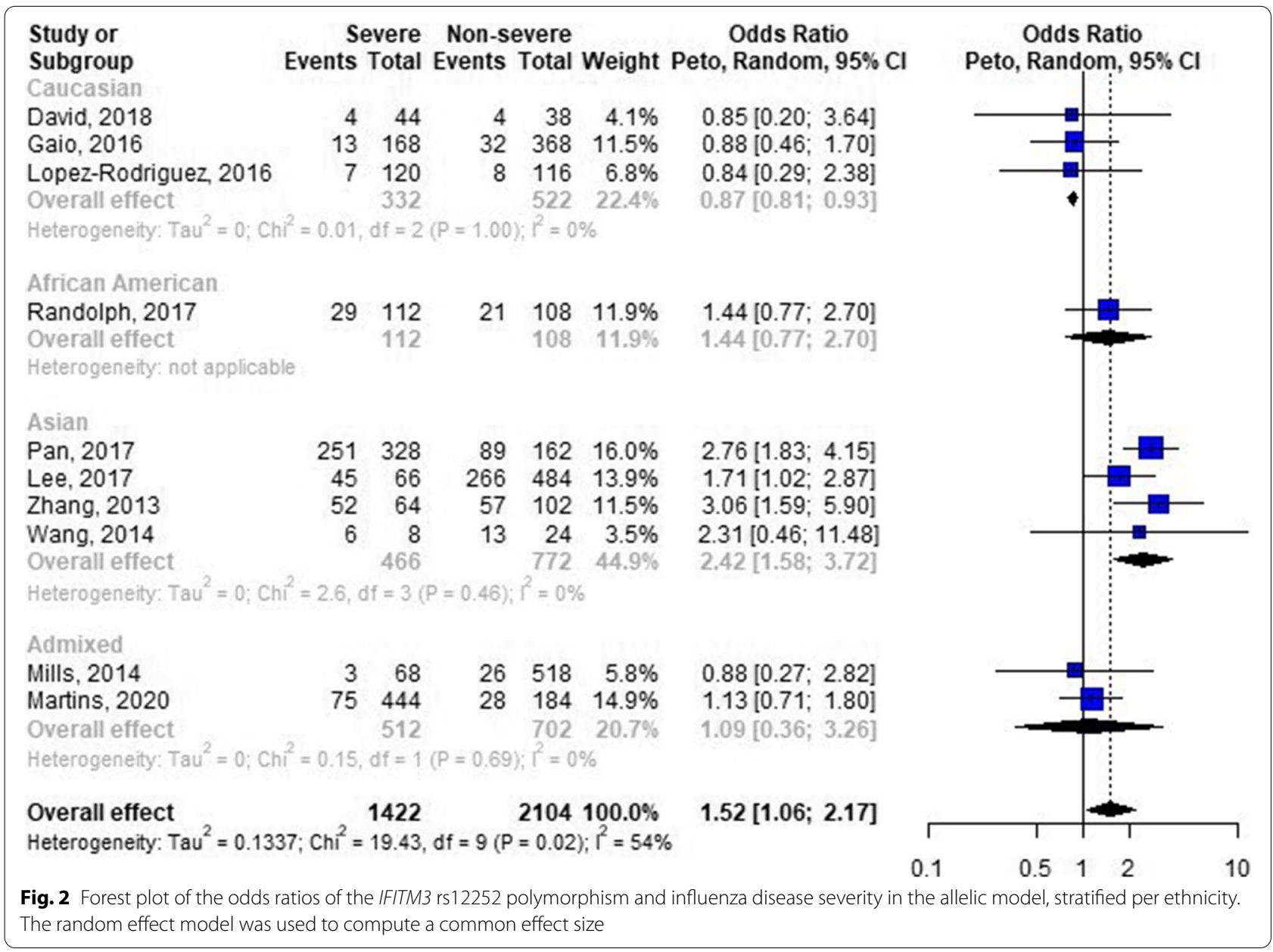


complement cascade (e.g. CD55 [45, 46], C1QBP [45] variants), variability at the collectin genes (e.g. $M B L 2$, SFTPA1, SFTPA2 variants [47-49]), or polymorphisms affecting the affinity of the immunoglobulin Fc receptor $(F C G R 2 A[45,50,51])$ or pattern-recognition receptors (e.g. TLR3 [30, 52], TLR2 [52], TLR4 [52] variants). Although some of the primary studies found evidence for a significant association between the human genetic polymorphism and influenza disease severity, only few associations were replicated within multiple independent cohorts.

We did find a significant pooled association for the IFITM3 SNP rs12252-C allele and severity of influenza infection, which is in line with previously published meta-analyses [53-56]. The protein product of IFITM3 restricts viral entry by blocking the fusion of host and viral membranes [57] and acts as a restriction factor affecting several stages of the viral replication cycle [58]. However, the prevalence of the rs12252-C allele is heterogeneously distributed among populations. Populationlevel studies suggested that this allele is rare in European cohorts, but frequent in the Han Chinese cohorts hospitalized with severe H1N1pdm09 infection [27, 33, 34, 59]. The higher allele frequency of IFITM 3 rs12252-C within the Han Chinese population may greatly increase the power of analysis [60] and partly explain the significant association found within these primary studies $[29,30,33,35]$, as opposed to studies conducted within European or African-American patient cohorts where the minor allele frequency is much lower and resulted in non-significant associations within these primary studies [27, 28, 32, 37]. Strikingly, the meta-analysis stratified per ethnicity found a protective effect of the rs12252-C allele in the Caucasian population. However, these findings are not in line with other meta-analyses that consistently found a harmful effect of the rs12252-C allele across different ethnic populations, although they investigated susceptibility to influenza infection and used the general healthy population (or healthy population in the 1000 Genomes project) as the control group [53, 56]. Still, the observed opposite effects may be due to possible linkage disequilibrium with other variants at IFITM3 or nearby genes of which the minor allele frequencies can also vary between populations $[27,29]$. Therefore, the susceptibility to severe influenza infection should rather be investigated based on haplotypes of the IFITM3 polymorphisms instead of single SNPs [59]. Further, the observed differences between populations in allele frequencies and the association with disease severity have implications for vaccination programs. Given the high frequency of the $\mathrm{C} / \mathrm{C}$ genotype in the Chinese population, individuals in East Asia with a $\mathrm{C} / \mathrm{C}$ genotype should be preferentially targeted for routine influenza vaccination [35].
Susceptibility to severe influenza in humans is likely to be polygenic and co-determined by viral characteristics, co-morbidities, and contextual factors [27]. In addition, the inconsistent evidence of the SNPs can be partially explained by the differences in the genetic background of the populations around the world [22]. As such, the lack of consistently replicated evidence within diverse populations pinpointing any specific genes in humans, advocates the use of large, hypothesis-free, genome-wide association studies [61]. Indeed, the potential role of individual polymorphisms might be diluted or masked by other gene-gene or gene-environment interactions [55]. Moreover, a single variant is often not informative for assessing disease risk given that genetic predisposition to most traits is spread and shared across a large number of variants [62]. Therefore, the effects of genetic variants should be investigated jointly by means of a genetic risk score [63]. The use of high-throughput sequencing technologies for human genetic association studies offers the ability to look at an increasing number of markers at once. Still, the inability to identify novel genetic risk factors for infectious diseases might be related to heterogeneity at the level of the infectious agent. Currently, the impact of host genetic variation is often studied separately from that of pathogen genomics. An integrative analysis, considering both host and viral genetic variation, will be highly informative [62].

Traditional journal formats often prevent the publication of summary data, such as genotype distributions, for each genetic marker that has been investigated in a genome-wide association study. Given these constraints, association studies investigating many genetic markers often only selectively report the most promising variants and existing results [30, 46-49, 64]. Next to selective reporting, reporting bias can also be the result of publication bias, which refers to suppression of evidence from an entire study based on its findings. Therefore, a literature-based systematic review can be prone to bias due to selective availability of published data [65].

Strengths of the current systematic review are the fact that the methodology, including eligibility criteria for study inclusion, search strategy, critical appraisal, and meta-analysis, was carefully planned with a detailed protocol prepared and registered in advance. In addition, the review was characterized by a comprehensive search without time limits, and which consulted both the MEDLINE and EMBASE bibliographic databases, as well as manual reference checking of included studies and existing reviews. The formulated inclusion and exclusion criteria were strictly applied and resulted in a homogenous collection of human genetic association studies. The review question focused on the severity of influenza infection, thereby excluding studies that only considered 
an influenza-negative (healthy) control group. As such, we required the case and control status to be determined by the severity of illness, which we consider as a more informative methodology for identifying genetic factors contributing to risk of severe illness as compared to studies comparing influenza-infected cases to healthy controls with unknown history of response to infection [31]. Previously published reviews were often restricted to a single polymorphism $[53,54,56]$, assessed the susceptibility to influenza infection [66], or were non-systematic $[19,20]$.

The severity of influenza infection can be defined based on multiple criteria and within different study populations. Individual studies may measure "hard" outcomes, such as mortality, to assess disease severity, or they can be based on clinical decisions, such as admission to the hospital or ICU. The criteria to admit a patient to the hospital or ICU used in different health units might not be uniform and could differ according to hospital-specific policies, epidemic alerts, and the indications of health authorities [34]. Also, for some of the studies there was no follow-up to confirm the outcome of non-severely ill patients. These differences in end-point definitions may hamper the comparison of results between studies. However, this was taken into account by performing subgroup analyses based on the study population (e.g., hospitalized vs ambulant patients) or definition of severity (e.g., mortality vs other severity indicators), and by using a random effect model to calculate the common OR. In addition to varying outcome definitions and study populations, primary studies often use different inheritance models without a biological justification available [67]. Instead of assuming a particular inheritance model and subsequently obtaining a single effect estimate during the meta-analysis [68], we obtained pooled estimates using four different genetic models.

\section{Conclusion}

The identification of host genetic factors, and their interaction with other host factors and viral characteristics, is of great importance for a better understanding of the biological predisposition of patients to severe complications. Here, we have identified several human genetic association studies leading to a significant effect of a genetic polymorphism and disease severity. However, with exception for the IFITM3 rs12252 polymorphism, we could not pinpoint specific genetic polymorphisms to be associated with severe influenza infection in a pooled meta-analysis. This could be due to heterogeneity between studies, but also because of the polygenic nature of infectious disease pathogenicity advocating the use of large genome-wide association studies and subsequent analyses based on haplotypes. A better knowledge of the host-pathogen interactions underlying the pathophysiology of influenza could also help to better understand the mechanisms of other respiratory pathogens, such as SARS-CoV-2.

\section{Methods}

The review was conducted in accordance with the guidelines from the HuGE review handbook for systematic review and meta-analysis of gene disease association studies [69] and was reported with respect to the Preferred Reporting Items for Systematic Reviews and Meta-Analyses (PRISMA) statement guidelines [70]. The protocol of the current review was registered on the PROSPERO International prospective register of systematic reviews (Trial Registration: CRD42020172583).

\section{Search strategy}

The MEDLINE and EMBASE electronic bibliographic databases were searched to identify relevant studies published before 5 July 2021. Three domains were included in the search using the PubMed search engine for the MEDLINE database: "host genetics", "influenza" and "severe infection". Each domain has several search terms combining $\mathrm{MeSH}$ terms and free text search to ensure that manuscripts containing any variation of each of the search terms were identified. The predefined search strategy used in PubMed and its adapted form to fit with the EMBASE database are presented in Additional file 3. In addition, reference lists of included studies and other reviews were examined (i.e., backward snowballing).

\section{Eligibility criteria}

Only primary studies enrolling individuals with a laboratory-confirmed influenza infection and allowing to compare severe cases with non-severe controls were considered. Severity had to be defined as: 1) severity indicators (e.g., intensive care unit (ICU) admission, invasive ventilation, or mortality) among hospitalized patients; 2) mortality among hospitalized patients; 3) mortality among hospitalized and ambulant patients; 4) severity indicators (e.g., ICU admission, invasive ventilation, or mortality) among hospitalized and ambulant patients; or 5) hospital admission among ambulant patients. Studies that investigated susceptibility to influenza infection itself, and thereby comparing influenza positive individuals to influenza negative individuals or healthy controls, were excluded. Further, this review only focused on studies conducted on human subjects within a real-life public health setting, so without taking into account animal, in vitro, or in silico studies. All genetic polymorphisms in the human genome, including bi-allelic single-nucleotide polymorphisms (SNPs) and bi-allelic insertion or deletion marker types, were considered as potential exposures. 
Studies based only on other marker types, such as microsatellites, short tandem repeats, aggregated haplotypes, or gene expression profiles were excluded. Finally, case reports, letters, comments, reviews, and editorials were excluded, as well as manuscript without an English full text available. A full list of exclusion and inclusion criteria can be found in Additional file 3. A first screening phase based on titles and abstracts was conducted [NVG] and out-of-topic studies were excluded. A second screening stage based on the full texts was conducted in duplicate by two independent reviewers [NVG, CD] using a standardized eligibility form. Any disagreement was solved by discussion. The studies that did match the eligibility criteria but that did not report the number of cases and controls for every genotype, as is often the case for genome-wide association studies (GWAS), were only included in the qualitative summary.

\section{Data extraction}

The following information was retrieved on a preconceived data extraction form in duplicate by two independent reviewers [NVG, CD]: the name of the first author, the country where the study was conducted, the year of publication, the study design (cohort or casecontrol), the sampling period, the setting, the patient selection criteria, the characteristics of the study population in terms of ethnicity and age groups, the influenza subtype(s), a description of cases and controls based on the severity, the genotyping method, and the SNPs/deletions/insertions and corresponding human genes that were investigated, number of eligible cases and controls, and the frequency of the alleles and genotype distributions for both the cases and controls. Genotype counts were extracted as raw numbers or were calculated from the reported percentages and total sample sizes. If the distribution of alleles was not given, it was calculated by genotype distribution. Some studies provided genotype distributions for more than one marker and were consequently represented with more than one data point in our database. Similarly, when multiple cases or control groups could be defined based on the severity within one study, they were either pooled or retained as multiple data points from the same study with a clear description of cases and controls in the data extraction. All data points were classified according to the study population and/or underlying definition of severity.

\section{Quality assessment}

The Confounding-Selection-Information (CSI) bias score developed by Patarčić et al [71] was used to evaluate the methodological quality of the included studies (Additional file 3). The elements of the score were developed on the basis of several existing assessment scores, including Venice criteria for assessing cumulative epidemiologic evidence in genetic associations [72], Newcastle-Ottawa case-control scale [73], and the Cochrane risk of bias tool [74]. The three domains, confounding, selection, and information, were scored in three grades of credibility: high $-\mathrm{A}$; intermediate $-\mathrm{B}$; or weak $-\mathrm{C}$. This scheme was applied to every data point and provided estimates ranging from the best AAA to the worst CCC score. When there was a post-hoc stratification of the study population into cases and controls, we assigned 0 to selection bias risk. As an additional quality check, the Hardy-Weinberg Equilibrium (HWE) test was recalculated for every control set included in the analysis. Data points that failed the HWE at the level $p<0.05$ were downgraded to $\mathrm{C}$ in the CSI score.

Risk of bias across studies was assessed using the Venice criteria [72] for the noteworthy meta-analysis results. Study power was scored on the basis of sample size (graded as A when over 10,000, as B when 1000-10,000, and as $C$ when less than 1000). Heterogeneity was based on the $\mathrm{I}^{2}$ statistic (graded as A when $0-25 \%$, as B when 26-50\%, and $C$ when over $50 \%$ ). The third score was fixed as $C$ (weak credibility), given the high risk of bias in primary studies (as demonstrated in the Results section).

\section{Statistical analysis}

The HWE was (re-)calculated for every control group of each included study using an exact test. A $p$-value $<0.05$ was considered as indication of a significant departure from HWE. Odds ratios (ORs) and 95\% confidence intervals (CI) were calculated anew from raw genotype and allele counts. Results from four different genetic models assuming different inheritance effects (allelic, heterozygous, homozygous, and dominant) were compared in order to provide broader insight into the underlying genetic architecture. In addition, a common OR and corresponding $p$-value based on the Armitage's trend test was calculated $[75,76]$. The calculated ORs correspond to taking the minor allele (with Minor Allele Frequency $(\mathrm{MAF})<0.5$ in the control group) as the risk allele. The HWE and ORs were calculated for each data point using a web tool (http://ihg.gsf.de/cgi-bin/hw/ hwa1.pl). A series of meta-analyses using four different genetic models (allelic, heterozygous, homozygous, and dominant) were performed for all markers where three or more data entries were available. For the purpose of the meta-analysis, the risk allele was uniformly defined for all data points based on literature, independently of the minor allele within individual studies. It was ensured that each data point in the meta-analysis represents an independent sample of data. When multiple cases or control groups were available in one study, the data point with the largest total sample size and/or focusing 
on severity (instead of only on mortality) was considered for the main analysis. The presence of heterogeneity was assessed using the Cochran's Q-test and quantified with the $I^{2}$ metric. A random effects model for meta-analysis was used to calculate the overall OR with their 95\% CI assuming differences in designs, severity definitions and ethnicity of individual studies. Peto's method was used to pool odds ratios [77]. Stratified analyses were performed, when appropriate, by ethnicity and the classification based on the underlying definition of severity and/ or study population. Leave-one-out analyses were performed to detect influential data points. Funnel plots [78] were used to assess potential publication bias. The "meta" package within $\mathrm{R}$ software version 4.0.2 was used for the meta-analyses [79].

\section{Abbreviations}

ACE: Angiotensin I converting enzyme; C1 QBP: Complement C1q binding protein; CCR5: C-C motif chemokine receptor 5; CD55: Complement decayaccelerating factor; $\mathrm{Cl}$ : Confidence interval; CSI: Confounding-SelectionInformation; CXCL14: C-X-C motif chemokine ligand 14; FCGR2A: FC fragment of IgG receptor Ila; GLDC: Glycine decarboxylase; GWAS: Genome-wide association studies; HWE: Hardy-Weinberg Equilibrium; ICU: Intensive care unit; IFITM3: Interferon-induced transmembrane protein 3; MAF: Minor allele frequency; MBL2: Mannose binding lectin 2; NGS: Next Generation Sequencing; NKG: Natural killer gene; OR: Odds ratio; PI3K: Phosphoinositide-3 kinase; PRISMA: Preferred Reporting Items for Systematic Reviews and Meta-Analyses; SARS-CoV-2: Severe acute respiratory syndrome coronavirus 2; SNP: Single Nucleotide Polymorphism; SFTP: surfactant protein; ST3GAL1: ST3 beta-galactoside alpha-2,3-sialyltransferase 1; TLR: Toll-like receptor; TMPRSS2: Transmembrane serine protease 2; TNF:Tumor necrosis factor; WGS: Whole-genome sequencing; WHO: World Health Organization.

\section{Supplementary Information}

The online version contains supplementary material available at https://doi. org/10.1186/s12864-021-08240-7.

Additional file 1. Data extraction of the included studies in the systematic review of host genetic factors and influenza disease severity.

Additional file 2. Results of the meta-analyses, leave-one-out analyses, and funnel plots for the association between the rs12252, rs333, rs1801274, and rs34481144 polymorphisms and influenza disease severity.

Additional file 3. Search strategy using the MEDLINE and EMBASE databases, eligibility criteria, and risk of bias score to assess the quality of included studies for the systematic review and meta-analysis of host genetic factors and influenza disease severity.

\section{Acknowledgements}

This research was supported by the BeREADY project financed by Sciensano. We apologize to all authors whose important work was not cited in the main text because of limitations of space.

\section{Authors' contributions}

Conceptualization: H.V.O., A.R., N.V.G.; Project Administration: N.R.; Data Curation: N.V.G., C.D.; Statistical Analysis: N.V.G., C.D., A.R.; Writing - Original Draft Preparation: N.V.G., C.D.; Writing - Review \& Editing: C.D., N.B., A.R., N.R., H.V.O.; Funding Acquisition: N.R.; Supervision: H.V.O., A.R.. N.R. and A.R. contributed equally as last author. The author(s) read and approved the final manuscript.

\section{Funding}

Not applicable.
Availability of data and materials

The dataset(s) supporting the conclusions of this article is (are) included within the article (and its additional file(s)).

\section{Declarations}

Ethics approval and consent to participate

Not applicable.

\section{Consent for publication}

Not applicable.

\section{Competing interests}

The authors declare that there are no conflict of interest.

\section{Author details}

${ }^{1}$ Scientific Directorate of Epidemiology and Public Health, Sciensano, J. Wytsmanstraat 14, 1050 Brussels, Belgium. ${ }^{2}$ Department of Epidemiology and Biostatistics, Institut de Recherche Expérimentale et Clinique, Faculty of Public Health, Université Catholique de Louvain, Clos Chapelle-aux-champs 30, 1200 Brussels, Belgium. ${ }^{3}$ Department of Public Health and Primary Care, Ghent University, De Pintelaan 185, 9000 Ghent, Belgium. ${ }^{4}$ Transversal Activities in Applied Genomics, Sciensano, J. Wytsmanstraat 14, 1050 Brussels, Belgium.

Received: 28 September 2021 Accepted: 7 December 2021

Published online: 20 December 2021

\section{References}

1. Martínez A, Soldevila N, Romero-Tamarit A, Torner N, Godoy P, Rius C, et al. Risk factors associated with severe outcomes in adult hospitalized patients according to influenza type and subtype. PLoS One. 2019;14(1):1-15.

2. Taylor G, Abdesselam K, Pelude L, Fernandes R, Mitchell R, McGeer A, et al. Epidemiological features of influenza in Canadian adult intensive care unit patients. Epidemiol Infect. 2016;144(4):741-50.

3. Loubet P, Samih-Lenzi N, Galtier F, Vanhems P, Loulergue P, Duval X, et al. Factors associated with poor outcomes among adults hospitalized for influenza in France: a three-year prospective multicenter study. J Clin Virol. 2016;79:68-73.

4. Coleman BL, Fadel SA, FitzpatrickT, Thomas S. Risk factors for serious outcomes associated with influenza illness in high- versus low- and middle-income countries: systematic literature review and meta-analysis. Influenza Other Respir Viruses. 2018;12(1):22-9.

5. Adlhoch C, Gomes Dias J, Bonmarin I, Hubert B, Larrauri A, Oliva Domínguez JA, et al. Determinants of fatal outcome in patients admitted to intensive care units with influenza, European Union 2009-2017. Open Forum Infect Dis. 2019;6(11):ofz462. https://doi.org/10.1093/ofid/ofz462 Cited 2021 Mar 23.

6. Taccone FS, Van Goethem N, De Pauw R, Wittebole X, Blot K, Van Oyen H, et al. The role of organizational characteristics on the outcome of COVID19 patients admitted to the ICU in Belgium. The Lancet Regional Health - Europe. 2020;100019. https://doi.org/10.1016/j.lanepe.2020.100019

7. Paget J, Spreeuwenberg P, Charu V, Taylor RJ, Iuliano AD, Bresee J, et al. Global mortality associated with seasonal influenza epidemics: new burden estimates and predictors from the GLaMOR project. J Glob Health. 2019;9(2) Available from: https://www.ncbi.nlm.nih.gov/pmc/articles/ PMC6815659/.

8. Gavigan P, McCullers JA. Influenza: annual seasonal severity. Curr Opin Pediatr. 2019;31(1):112-8.

9. Freitas ARR, Donalisio MR. Excess of mortality in adults and elderly and circulation of subtypes of influenza virus in southern Brazil. Front Immunol. 2017:8:1903.

10. Martínez A, Soldevila N, Romero-Tamarit A, Torner N, Godoy P, Rius C, et al. Risk factors associated with severe outcomes in adult hospitalized patients according to influenza type and subtype. PLoS One. 2019;14(1):e0210353.

11. Su S, Chaves SS, Perez A, D'Mello T, Kirley PD, Yousey-Hindes K, et al. Comparing clinical characteristics between hospitalized adults with 
laboratory-confirmed influenza A and B virus infection. Clin Infect Dis. 2014;59(2):252-5.

12. Nelson Ml, Holmes EC. The evolution of epidemic influenza. Nat Rev Genet. 2007;8(3):196-205.

13. Simon B, Pichon M, Valette $M$, Burfin $G$, Richard $M$, Lina B, et al. Whole genome sequencing of $A(\mathrm{H} 3 \mathrm{~N} 2)$ influenza viruses reveals variants associated with severity during the $2016^{-} 2017$ season. Viruses. 2019;11(2):108

14. Van Goethem N, Robert A, Bossuyt N, Van Poelvoorde LAE, Quoilin S, De Keersmaecker SCJ, et al. Evaluation of the added value of viral genomic information for predicting severity of influenza infection. BMC Infect Dis. 2021;21(1):785

15. Bourdon M, Manet C, Montagutelli X. Host genetic susceptibility to viral infections: the role of type I interferon induction. Genes Immun. 2020:21(6):365-79.

16. Elhabyan A, Elyaacoub S, Sanad E, Abukhadra A, Elhabyan A, Dinu V. The role of host genetics in susceptibility to severe viral infections in humans and insights into host genetics of severe COVID-19: a systematic review. Virus Res. 2020;289:198163.

17. LoPresti M, Beck DB, Duggal P, Cummings DAT, Solomon BD. The role of host genetic factors in coronavirus susceptibility: review of animal and systematic review of human literature. Am J Hum Genet. 2020;107(3):381-402.

18. To KKW, Zhou J, Chan JFW, Yuen KY. Host genes and influenza pathogenesis in humans: an emerging paradigm. Curr Opin Virol. 2015;14:7-15.

19. Clohisey S, Baillie JK. Host susceptibility to severe influenza A virus infection. Crit Care. 2019;23(1):1-10.

20. Gounder AP, Boon ACM. Influenza pathogenesis: the role of host factors on severity of disease. J Immunol. 2019;202(2):341-50.

21. Wellington D, Laurenson-Schafer $\mathrm{H}$, Abdel-Haq A, Dong T. IFITM3: how genetics influence influenza infection demographically. Biom J. 2019:42(1):19-26.

22. Pérez-Rubio G, Ponce-Gallegos MA, Domínguez-Mazzocco BA, PonceGallegos J, García-Ramírez RA, Falfán-Valencia R. Role of the host genetic susceptibility to 2009 pandemic influenza A H1N1. Viruses. 2021;13(2):344.

23. World Health Organization. WHO public health research agenda for influenza: 2017 update. 2017.

24. Alcaïs $A$, Abel L, Casanova J-L. Human genetics of infectious diseases: between proof of principle and paradigm. J Clin Invest. 2009;119(9):2506-14.

25. Lee YH. Meta-analysis of genetic association studies. Ann Lab Med. 2015;35(3):283-7.

26. Ioannidis JPA. Genetic associations: false or true? Trends Mol Med. 2003:9(4):135-8

27. David S, Correia V, Antunes L, Faria R, Ferrão J, Faustino P, et al. Population genetics of IFITM3 in Portugal and Central Africa reveals a potential modifier of influenza severity. Immunogenetics. 2018;70(3):169-77.

28. Randolph AG, Yip W-K, Allen EK, Rosenberger CM, Agan AA, Ash SA, et al. Evaluation of IFITM3 rs12252 association with severe pediatric influenza infection. J Infect Dis. 2017;216(1):14-21.

29. Pan Y, Yang P, Dong T, Zhang Y, Shi W, Peng X, et al. IFITM3 Rs12252-C variant increases potential risk for severe influenza virus infection in Chinese population. Front Cell Infect Microbiol. 2017;7:294.

30. Lee N, Cao B, Ke C, Lu H, Hu Y, Tam CHT, et al. IFITM3, TLR3, and CD55 gene SNPs and cumulative genetic risks for severe outcomes in Chinese patients with H7N9/H1N1 pdm09 influenza. J Infect Dis. 2017:216(1):97-104

31. Allen EK, Randolph AG, Bhangale T, Dogra P, Ohlson M, Oshansky CM, et al. SNP-mediated disruption of CTCF binding at the IFITM3 promoter is associated with risk of severe influenza in humans. Nat Med. 2017;23(8):975-83.

32. Mills TC, Rautanen A, Elliott KS, Parks T, Naranbhai V, leven MM, et al. IFITM3 and susceptibility to respiratory viral infections in the community. J Infect Dis. 2014;209(7):1028-31.

33. Zhang Y-H, Zhao Y, Li N, Peng Y-C, Giannoulatou E, Jin R-H, et al. Interferon-induced transmembrane protein-3 genetic variant rs $12252-\mathrm{C}$ is associated with severe influenza in Chinese individuals. Nat Commun. 2013:4:1418.

34. Gaio V, Nunes B, Pechirra P, Conde P, Guiomar R, Dias CM, et al. Hospitalization risk due to respiratory illness associated with genetic variation at
IFITM3 in patients with influenza A(H1N1)pdm09 infection: a case-control study. PLoS One. 2016;1 1(6):e0158181.

35. Wang Z, Zhang A, Wan Y, Liu X, Qiu C, Xi X, et al. Early hypercytokinemia is associated with interferon-induced transmembrane protein-3 dysfunction and predictive of fatal H7N9 infection. PNAS. 2014;111(2):769-74.

36. López-Rodríguez M, Herrera-Ramos E, Solé-Violán J, Ruíz-Hernández JJ, Borderías L, Horcajada JP, et al. IFITM3 and severe influenza virus infection. No evidence of genetic association. Eur J Clin Microbiol Infect Dis. 2016:35(11):1811-7.

37. Martins JSC, Oliveira MLA, Garcia CC, Siqueira MM, Matos AR. Investigation of human IFITM3 polymorphisms rs34481144A and rs12252C and risk for influenza $\mathrm{A}(\mathrm{H} 1 \mathrm{~N} 1)$ pdm09 severity in a Brazilian cohort. Front Cell Infect Microbiol. 2020;10:352.

38. Cheng Z, Zhou J, To KK-W, Chu H, Li C, Wang D, et al. Identification of TMPRSS2 as a susceptibility gene for severe 2009 pandemic $A(H 1 N 1)$ influenza and A(H7N9) influenza. J Infect Dis. 2015;212(8):1214-21.

39. Zhou J, Wang D, Wong BH-Y, Li C, Poon VK-M, Wen L, et al. Identification and characterization of GLDC as host susceptibility gene to severe influenza. EMBO Mol Med. 2019;1 1(1) Available from: http://www.embase. $\mathrm{com} / \mathrm{search} /$ results? subaction=viewrecord\&from $=$ export\&id $=\mathrm{L} 6252$ 86083.

40. Antonopoulou A, Baziaka F, Tsaganos T, Raftogiannis M, Koutoukas P, Spyridaki A, et al. Role of tumor necrosis factor gene single nucleotide polymorphisms in the natural course of 2009 influenza A H1N1 virus infection. Int J Infect Dis. 2012;16(3):e204-8.

41. Matos AR, Martins JSCC, Oliveira MDLA, Garcia CC, Siqueira MM. Human CCR5 32 (rs333) polymorphism has no influence on severity and mortality of influenza $\mathrm{A}(\mathrm{H} 1 \mathrm{~N} 1)$ pdm09 infection in Brazilian patients from the post pandemic period. Infect Genet Evol. 2019;67:55-9.

42. Falcon A, Cuevas MT, Rodriguez-Frandsen A, Reyes N, Pozo F, Moreno $\mathrm{S}$, et al. CCR5 deficiency predisposes to fatal outcome in influenza virus infection. J Gen Virol. 2015;96(8):2074-8.

43. Maestri A, dos Santos MC, Ribeiro-Rodrigues EM, de Mello WA, Sousa RCM, dos Santos SE, et al. The CCR5 $\triangle 32$ ( $r s 333$ ) polymorphism is not a predisposing factor for severe pandemic influenza in the Brazilian admixed population. BMC Res Notes. 2015:8(1):326.

44. Sironi M, Cagliani R, Pontremoli C, Rossi M, Migliorino G, Clerici M, et al. The CCR5 $\triangle 32$ allele is not a major predisposing factor for severe H1N1 pdm09 infection. BMC Res Notes. 2014;7:504.

45. Chatzopoulou F, Gioula G, Kioumis I, Chatzidimitriou D, Exindari M. Identification of complement-related host genetic risk factors associated with influenza $\mathrm{A}(\mathrm{H} 1 \mathrm{N1}$ )pdm09 outcome: challenges ahead. Med Microbiol Immunol. 2019;208(5):631-40.

46. Zhou J, To KK-W, Dong H, Cheng Z-S, Lau CC-Y, Poon VKM, et al. A functional variation in CD55 increases the severity of 2009 pandemic H1N1 influenza A virus infection. J Infect Dis. 2012;206(4):495-503.

47. Herrera-Ramos E, López-Rodríguez M, Ruíz-Hernández JJ, Horcajada JP, Borderías L, Lerma E, et al. Surfactant protein A genetic variants associate with severe respiratory insufficiency in pandemic influenza $A$ virus infection. Crit Care. 2014;18(3) Available from: http://www.embase.com/ search/results?subaction=viewrecord\&from=export\&id=L53202324.

48. Levy E, Yip W-K, Mistry A, Super M, McLaughlin G, Sapru A, et al. Association of mannose-binding lectin with influenza critical illness in children. Crit Care Med. 2018;46(1):21

49. To KKW, Zhou J, Song Y-Q, Hung IFN, Ip WCT, Cheng Z-S, et al. Surfactant protein $B$ gene polymorphism is associated with severe influenza. Chest. 2014:145(6):1237-43.

50. Maestri A, Sortica VA, Ferreira DL, de Almeida Ferreira J, Amador MA, de Mello WA, et al. The His131 Arg substitution in the FCGR2A gene (rs1801274) is not associated with the severity of influenza A(H1N1) pdm09 infection. BMC Res Notes. 2016;9(1):296.

51. Chan JF-W, To KK-W, Tse H, Lau CC-Y, Li IW-S, Hung IF-N, et al. The lower serum immunoglobulin $\mathrm{G} 2$ level in severe cases than in mild cases of pandemic H1N1 2009 influenza is associated with cytokine dysregulation. Clin Vaccine Immunol. 2011;18(2):305-10.

52. Esposito S, Molteni CG, Giliani S, Mazza C, Scala A, Tagliaferri L, et al. Toll-like receptor 3 gene polymorphisms and severity of pandemic $A$ H1N1/2009 influenza in otherwise healthy children. Virol J. 2012;9(1):270.

53. Prabhu SS, Chakraborty TT, Kumar N, Banerjee I. Association between IFITM3 rs 12252 polymorphism and influenza susceptibility and severity: a meta-analysis. Gene. 2018;674:70-9. 
54. Xuan Y, Wang LN, Li W, Zi HR, Guo Y, Yan WJ, et al. IFITM3 rs12252 T>C polymorphism is associated with the risk of severe influenza: a metaanalysis. Epidemiol Infect. 2015;143(14):2975-84.

55. Yang X, Tan B, Zhou X, Xue J, Zhang X, Wang P, et al. Interferon-inducible transmembrane protein 3 genetic variant rs12252 and influenza susceptibility and severity: a meta-analysis. PLoS One. 2015;10(5) Available from: http://www.embase.com/search/results?subaction=viewrecord\&from= export\&id $=\mathrm{L} 604276481$.

56. Chen T, Xiao M, Yang J, Chen YK, Bai T, Tang XJ, et al. Association between rs12252 and influenza susceptibility and severity: an updated meta-analysis. Epidemiol Infect. 2019;147 Available from: https://www.cambridge. org/core/journals/epidemiology-and-infection/article/association-betwe en-rs12252-and-influenza-susceptibility-and-severity-an-updated-metaa nalysis/C4CDD9859009E74117FE02F3C4A6A8CA. Cited 2021 Aug 31.

57. Desai TM, Marin M, Chin CR, Savidis G, Brass AL, Melikyan GB. IFITM3 restricts influenza A virus entry by blocking the formation of fusion pores following virus-endosome hemifusion. PLoS Pathog. 2014;10(4):e1004048.

58. Brass AL, Huang I-C, Benita Y, John SP, Krishnan MN, Feeley EM, et al. The IFITM proteins mediate cellular resistance to influenza a H1N1 virus, West Nile virus, and dengue virus. Cell. 2009;139(7):1243-54.

59. Kim Y-C, Jeong B-H. Ethnic variation in risk genotypes based on single nucleotide polymorphisms (SNPs) of the interferon-inducible transmembrane 3 (IFITM3) gene, a susceptibility factor for pandemic 2009 H1N1 influenza A virus. Immunogenetics. 2020;72(9):447-53.

60. The 1000 Genomes Project Consortium. An integrated map of genetic variation from 1,092 human genomes. Nature. 2012:491(7422):56-65.

61. Horby P, Nguyen NY, Dunstan SJ, Baillie JK. The role of host genetics in susceptibility to influenza: a systematic review. PLoS One. 2012;7(3) Available from: http://www.embase.com/search/results?subaction=viewr ecord\&from $=$ export\&id $=L 364439054$

62. Kwok AJ, Mentzer A, Knight JC. Host genetics and infectious disease: new tools, insights and translational opportunities. Nat Rev Genet. 2021;22(3):137-53.

63. Lewis $C M$, Vassos E. Polygenic risk scores: from research tools to clinical instruments. Genome Med. 2020;12(1):44.

64. Chen L, Lei Y, Zhang L. Role of C-X-C motif chemokine ligand 14 promoter region DNA methylation and single nucleotide polymorphism in influenza A severity. Respir Med. 2021;185 Available from: https://www.resme djournal.com/article/S0954-6111(21)00168-2/abstract. Cited 2021 Sep 8.

65. Sagoo GS, Little J, Higgins JPT. Systematic reviews of genetic association studies. PLoS Med. 2009;6(3):e1000028.

66. Horby P, Nguyen NY, Dunstan SJ, Kenneth Baillie J. An updated systematic review of the role of host genetics in susceptibility to influenza. Influ Other Respir Viruses. 2013;7(SUPPL.2):37-41.

67. Minelli C, Thompson JR, Abrams KR, Thakkinstian A, Attia J. The choice of a genetic model in the meta-analysis of molecular association studies. Int J Epidemiol. 2005;34(6):1319-28.

68. Salanti G, Higgins JPT. Meta-analysis of genetic association studies under different inheritance models using data reported as merged genotypes. Stat Med. 2008;27(5):764-77.

69. Little J, Higgins JPT. The HuGENet ${ }^{\mathrm{TM}}$ HuGE review handbook, version 1.0: Centers for Disease Control and Prevention; 2006. Available from: http:// www.hugenet.ca

70. Moher D, Liberati A, Tetzlaff J, Altman DG. Preferred reporting items for systematic reviews and meta-analyses: the PRISMA statement. BMJ. 2009;339:b2535.

71. Patarčić I, Gelemanović A, Kirin M, Kolčić I, Theodoratou E, Baillie KJ, et al. The role of host genetic factors in respiratory tract infectious diseases: systematic review, meta-analyses and field synopsis. Sci Rep. 2015;5:16119

72. Ioannidis JPA, Boffetta P, Little J, O'Brien TR, Uitterlinden AG, Vineis P, et al. Assessment of cumulative evidence on genetic associations: interim guidelines. Int J Epidemiol. 2008;37(1):120-32.

73. Wells G, Shea B, O'Connell D, Peterson J, Welch V, Losos M, et al. The Newcastle-Ottawa Scale (NOS) for assessing the quality of nonrandomised studies in meta-analyses. 2013. Available from: http://www.ohri.ca/progr ams/clinical_epidemiology/oxford.asp.

74. Higgins, J.P.T. Cochrane handbook for systematic reviews of interventions version 5.1.0. 2011. Available from: http://www.cochrane-handbook.org.
75. Clarke GM, Anderson CA, Pettersson FH, Cardon LR, Morris AP, Zondervan KT. Basic statistical analysis in genetic case-control studies. Nat Protoc. 2011:6(2):121-33.

76. Armitage P. Tests for linear trends in proportions and frequencies. Biometrics. 1955:11(3):375-86.

77. Yusuf S, Peto R, Lewis J, Collins R, Sleight P. Beta blockade during and after myocardial infarction: an overview of the randomized trials. Prog Cardiovasc Dis. 1985;27(5):335-71.

78. Sterne JA, Egger M. Funnel plots for detecting bias in meta-analysis: guidelines on choice of axis. J Clin Epidemiol. 2001;54(10):1046-55.

79. R software. meta-package function. Available from: https://www.rdocu mentation.org/packages/meta/versions/4.18-2/topics/meta-package. Accessed 13 Dec 2021

\section{Publisher's Note}

Springer Nature remains neutral with regard to jurisdictional claims in published maps and institutional affiliations.

Ready to submit your research? Choose BMC and benefit from

- fast, convenient online submission

- thorough peer review by experienced researchers in your field

- rapid publication on acceptance

- support for research data, including large and complex data types

- gold Open Access which fosters wider collaboration and increased citations

- maximum visibility for your research: over 100M website views per year

At $\mathrm{BMC}$, research is always in progress.

Learn more biomedcentral.com/submissions 